THE activation of complement and contact systems occurs in reperfusion injuries with initial tissue hypoxia, and lactic acidosis such as mycardial infarction and birth asphyxia. The aim of our experiment was the formal proof of activation by sole lactic acidosis. Lactic acid was added to blood and plasma samples from 10 healthy volunteers. C5a and factor XIIa were measured by EIA after incubation at $37^{\circ} \mathrm{C}$ for $1 \mathrm{~h}$. Both concentrations increased $(P<0.0001$ by Friedman analysis) in blood and plasm a samples with increasing amount of added lactic acid. Lactic acidos is can activate $\mathrm{C} 5$ from the complement system and factor XII from the contact system directly, even in the absence of cellular components.

Key words: Lactic acidosis, Complement system, Contact system, Hageman factor, C5a

\section{In vitro activation of complement and contact system by lactic acidosis}

\section{J. Sonntag, ${ }^{\text {CA }}$ M. Emeis, E. Strauss, M. Obladen}

Department of Neonatology, Charité-VirchowKlinikum, Humboldt Universität Berlin

\author{
${ }^{\mathrm{CA}}$ Corresponding Author \\ Tel: $(+49) 3045066463$ \\ Fax: (+49) 3045066922
}

\section{Introduction}

Activation of complement and contact system has been described in reperfusion injuries with tissue hypoxia and lactic acidosis such as mycardial infarction, birth asphyxia, and gut ischaemia. ${ }^{1-4}$ Contact with membrane or mitochondrial fractions and other subcellular components of destroyed cells as well as reaction to other mediators and receptor changes may cause activation. Complement and contact system participate in the pathogenesis of shock and tissue injury after initial activation. ${ }^{1,2,4}$ The aim of this study was to investigate the direct effect of lactic acidosis on the activation of $\mathrm{C} 5$ from the complement system and on factor XII from the contact system in vitro. ${ }^{5,6,7}$. To distinguish the effect of cellular components on these activations we performed our tests with blood and plasma.

\section{Material and Methods}

Twenty ml blood samples from 10 healthy volunteers aged 25-40 years were collected in tubes with 400 I.E. Heparin. Heparin blood was filled into six polypropylene tubes of $1 \mathrm{ml}$ portions. The leftover of $14 \mathrm{ml}$ heparin blood was centrifuged immediately at $4^{\circ} \mathrm{C}$ for $10 \mathrm{~min}$ at $3000 \mathrm{~g}$. The resulting plasma was separated and filled into six tubes of $1 \mathrm{ml}$ portions. Anhydrous lactate (Sigma-Aldrich, Deisenhofen, Germany) dissolved in steril water were added in amounts of $0.2 \mathrm{mg}(2.2 \mu \mathrm{mol}), 0.5 \mathrm{mg}(5.5 \mu \mathrm{mol})$, $1 \mathrm{mg}(11.1 \mu \mathrm{mol})$, or $2 \mathrm{mg}(22.2 \mu \mathrm{mol})$ either to blood or plasma sample and one blood and plasma sample was left natively. All 10 portions were incubated in a water bath at $37^{\circ} \mathrm{C}$ for $1 \mathrm{~h}$. One blood and one plasma sample were centrifuged before incubation and stored at $-80^{\circ} \mathrm{C}$ to be used as start value. After incubation $1 \mathrm{mg}$ disodium-ethylenediaminetetra-acetic acid (EDTA) was added to stop complement activation ${ }^{5}$ and the samples were centrifuged, separated and stored. Blood-pH, potassium and lactate concentration were examined in the heparin blood samples before and after lactate addition by Ciba Corning 865 (Fernwald, Germany). Changes in plasma $\mathrm{pH}$-value by added lactic acid were similar as in blood samples and therefore not reported separately.

Reliability of test results was monitored using controls with known concentrations of $\mathrm{C} 5 \mathrm{a}$ and factor XIIa. C5a was determined with a specific sandwich EIA $^{8}$ (Fa. Behring, Marburg, Germany) and showed a variation coefficient $(n=20)$ of $8 \%$ The concentration of activated factor XIIa was measured by a semi-quantitative direct immunoassay ${ }^{9}$ (WAKChemie Medical GmbH, Bad Homburg, Germany), and showed a variation coefficient $(n=20)$ of $6 \%$ Both EIAs did not depend on pH-value in the sample.

\section{Statistical analysis}

As most data were not normally distributed, results were expressed as median with quartiles. Changes with increasing lactic acid concentrations were compared with variance analysis (Friedman test). Differences in C5a and factor XIIa between blood and plasma were assessed by multi variance analysis (MANOVA) for repeated measures. Statistical sig- 


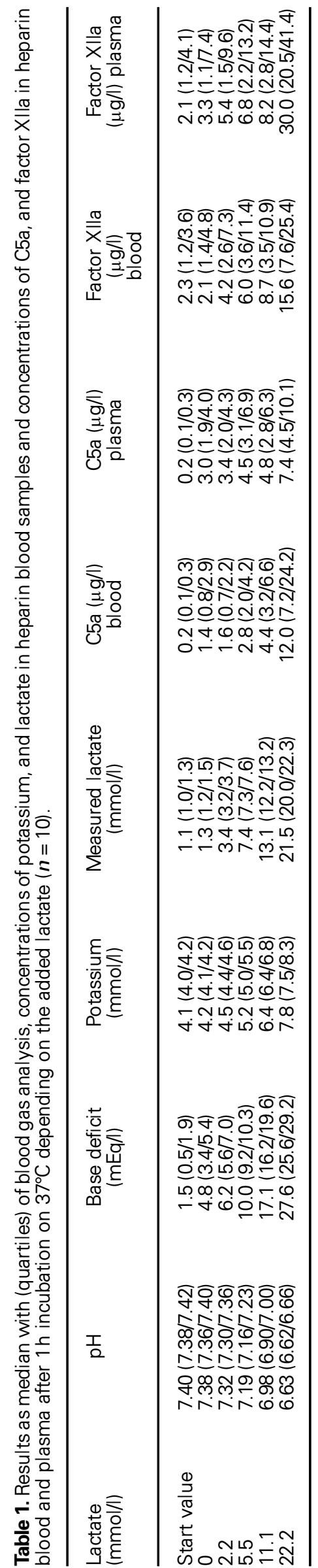

nificance was assumed at $P<0.05$. All calculations were performed by means of the software package SPSS-PC (Chicago, Illinois, USA).

\section{Results}

The influence of lactate addition on $\mathrm{pH}$, base deficit, measured lactate, and potassium concentrations in blood and C5a and factor XIIa concentrations in blood and plasma are shown in Table 1. Lactate and potassium concentration as well as base deficit increased with the amount of added lactic acid to the samples $(P<0.0001)$. C5a and factor XIla concentrations increased $(P<0.0001)$ and differences were found for C5a $(P<0.001)$ and factor XIIa $(P<0.005)$ between blood and plasma samples.

\section{Discussion}

The activation of complement and contact system is reported in several conditions associated with tissue acidosis. After birth asphyxia both systems were activated in blood pH-values below 7.10. The lowest value of the $\mathrm{pH}$ at inflammatory tissue has been reported to be $5.5-6.5 .^{10}$ The diagnostic criteria for lactic acidosis include a $\mathrm{pH}$ less than 7.35 and blood lactate concentration greater than $5 \mathrm{mmol} / \mathrm{l}^{11}$ Therefore, the described in vitro model investigates in clinical relevant ranges.

The elevated C5a and factor XIIa values in our series indicate that lactic acidosis can activate parts of the complement and contact system in plasma and blood. As shown by the similar rise in plasma samples, no cellular interaction or contact with destroyed cells is necessary to initiate the complement and contact cascade in acidosis. The differences between heparin blood and plasma may be due to two factors: (1) binding of C5a and factor XIIa to receptors of blood cells, ${ }^{12}$ which results in lower C5a and factor XIIa values in blood compared with plasma by low amount of added lactic acid; and (2) additional activation by contact with destroyed cell membranes and receptor changes in blood, which results in higher $\mathrm{C5}$ a and factor XIIa values in blood samples by lower $\mathrm{pH}$ values causing cell destruction. This haemolytic effect is documented by raising potassium concentration in the samples.

Fishelson et $a l^{13}$ reported that at $\mathrm{pH} 6.4$ the generation of the $\mathrm{C} 3$ convertase of the alternative pathway is increased in blood samples. The classical pathway and the plasma contact system may be activated by conformational changes of C-reactive protein, which results in binding to negatively charged surfaces in acidosis. ${ }^{10}$ However, the C5 convertase, which are instrumental in activating $\mathrm{C} 5$ with the release of $\mathrm{C} 5 \mathrm{a}$, need a surface upon which the tri-molecular complement protein complexes can assemble. Therefore, the development of $\mathrm{C} 5 \mathrm{a}$ in 
plasma samples is difficult to explain without granulocytes. Hammer et al. ${ }^{14}$ reported a complement activation with cleavage of $\mathrm{C} 5$ in serum independent of the classical or alternative pathway by $\mathrm{pH} 6.4$, but without development of C5a. Thus, our results may be show that another proteinase is activated by acidosis in plasma, which then cleaves C5 to C5a without any role of the complement convertase. Alternatively, cells remaining in the plasma might provide surfaces for complement convertase assembly.

\section{Conclusion}

Lactic acidosis can activate parts of the complement and contact system directly, even in absence of cellular components. Further studies should be directed to determine the mechanisms for activation of $\mathrm{C} 5$ and factor XII by lactic acidosis.

\section{References}

1. Murdoch J, Hall R Brain protection: physiological and pharmacological considerations. Part I: The physiology of brain injury. Can J Anaesth 1990; 37: 663-671.

2. Horstick G, Heimann A, Götze $\mathrm{O}$ et al. Intracoronary application of $\mathrm{Cl}$ esterase inhibitor improves cardiac function and reduces myocardial necrosis in an experimental model of ischemia and reperfusion. Circulation 1997; 95: 701-708.

3. Wagner MH, Sonntag J, Waiss E, Obladen M. Complement activation after birth asphyxia. Pediatr Res 1996; 40: 556.
4. Hill J, Lindsay TF, Ortiz F, Yeh CG, Hechtman HB, Moore FD Jr. Soluble complement receptor type 1 ameliorates the local and remote organ injury after intestinal ischemia-reperfusion in the rat. J Im munol 1992; 149: $1723-1728$

5. Chang TM, Lister CW. Assessment of blood substitutes: II. In-vitro complement activation of human plasma and blood for safety studies in research, development, industrial production and preclinical analysis. Artif Cells Blood Substit Immob Biotechnol 1994; 22: 171-180.

6. Van der Kamp KW, Hauch KD, Feijen J, Horbett TA. Contact activation during incubation of five different polyurethanes or glass in plasma. $J$ Biomed Mater Res 1995; 29: 1303-1306.

7. Vandenberg RJ, Easterbrook-Smith SB. Activation of the classical complement pathway by BioRex-70. Imm unol Lett 1987; 14: 155-158.

8. Klos A, Ihrig V, Messmer M, Grabbe J, Bitter-Suermann D. Detection of native human complement componenets $\mathrm{C} 3$ and $\mathrm{C} 5$ and their primary activation peptides C3a and C5a (anaphylatoxic peptides) by EUSAs with monoclonal antibodies. I Im munol Methods 1988; 111: 241-252.

9. Ford RP, Esnouf MP, Burgess AI, Sarphie A. An enzymetinked immunsorbent assay (ELISA) for the measurement of activated factor XII (Hageman factor) in human plasma. I Immunoassay 1996; 17: 119-131.

10. Miyazawa K, Inoue K. Complement activation by human Greactive prote in in mildly acidic conditions. J Im munol 1990; 145: 650-654.

11. Mizock BA. Lactic acidosis. Dis Mon 1989: 35: 233-300.

12. Hetland G, Moen O, Bergh K. Both plasma-and le ukocyte-associated C5a are essential for assessment of C5a generation in vivo. Ann Thorac Surg 1997; 63: 1076-1080.

13. Fishelson Z, Horstman RD, Miller-Eberhard HJ. Regulation of the alternative pathway of complement by pH. J Immunol 1987; 138: 3392-3395.

14. Hammer $\mathrm{CH}$, Hansch G, Gresham HD, Shin ML Activation of the fifth and sixth components of the human complement system: C6-dependent cleavage of $\mathrm{C} 5$ in acid and the formation of a bimolecular lytic complex. J Immunol 1983; 131: 892-898.

ACKNOWLEDGEMENT. This work was supported by the German Research Society (DFG-Ob 43/6-2).

\section{Received 19 September 1997; accepted in revised form 18 October 1997}




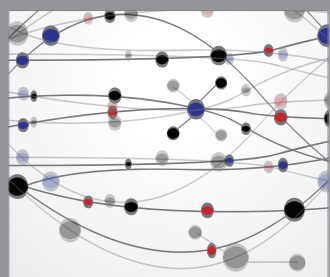

The Scientific World Journal
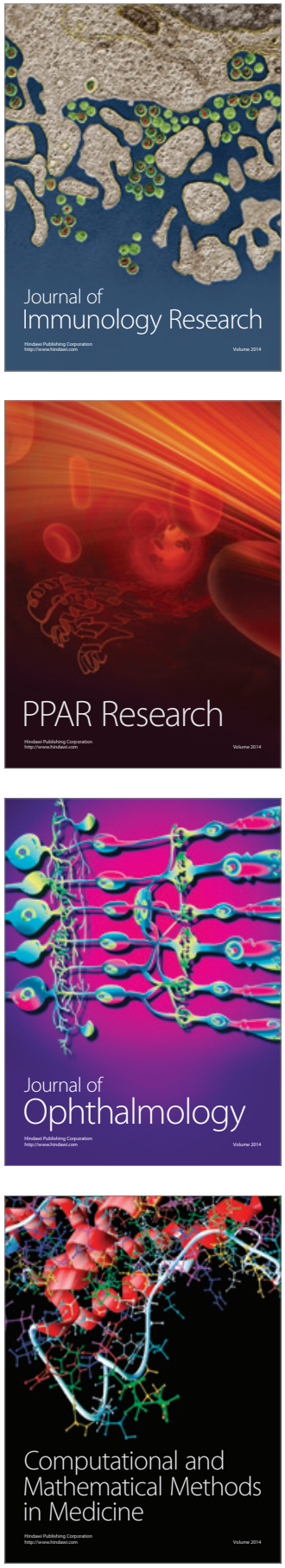

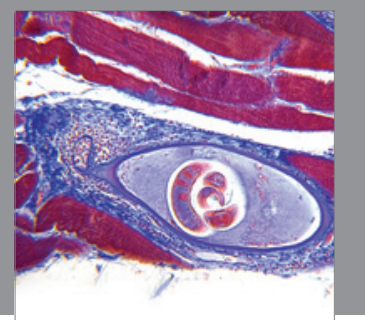

Gastroenterology

Research and Practice
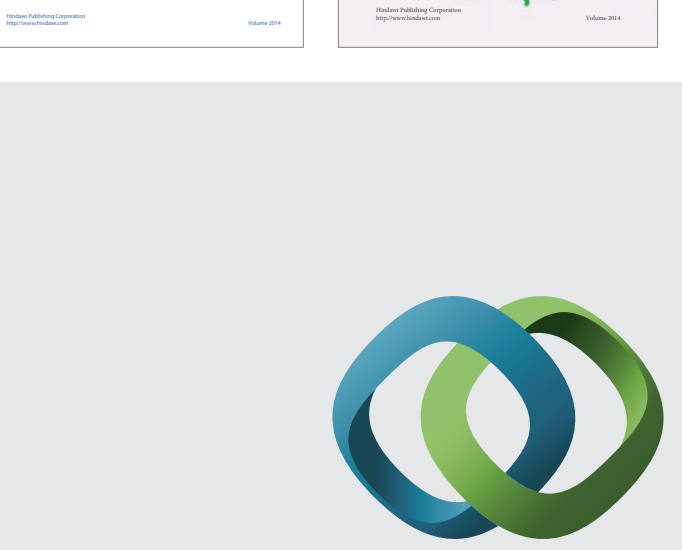

\section{Hindawi}

Submit your manuscripts at

http://www.hindawi.com
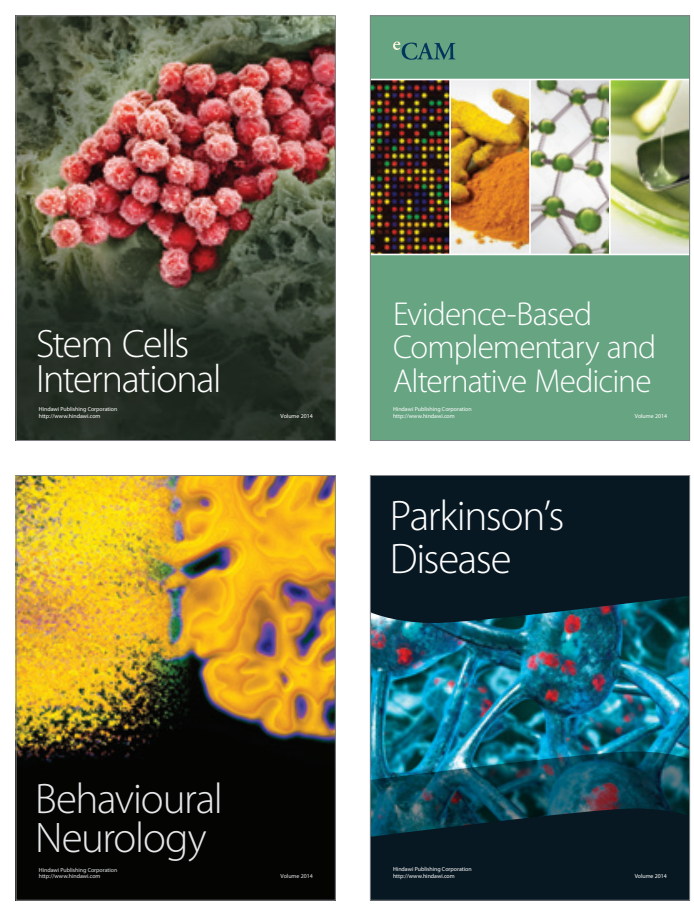

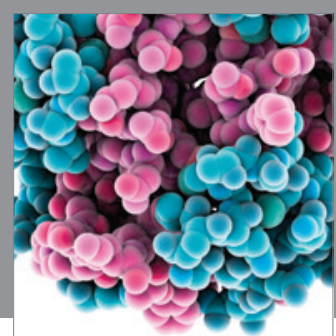

Journal of
Diabetes Research

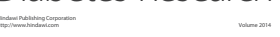

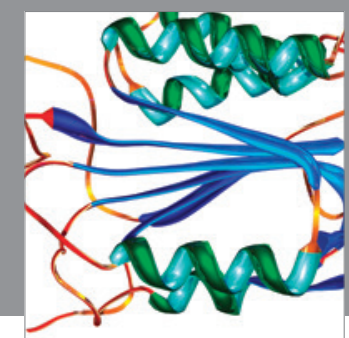

Disease Markers
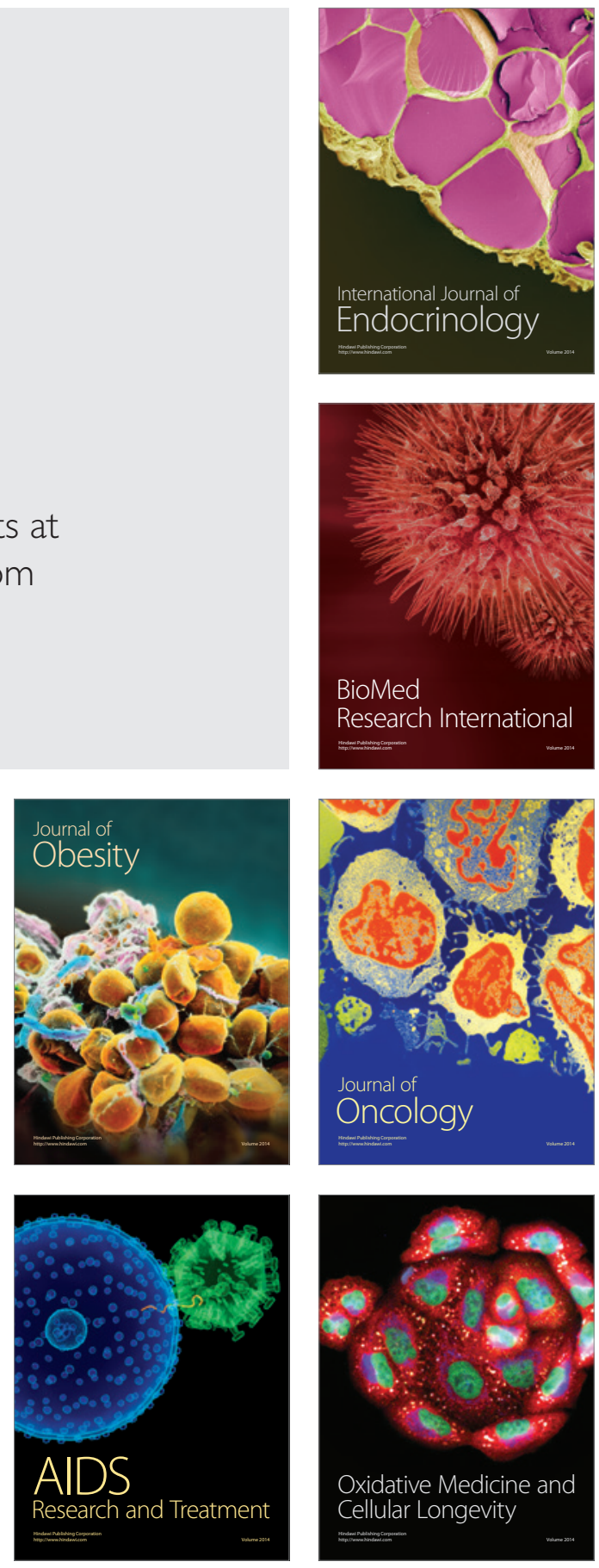